\title{
Prevalence of chlamydial antibody in Malaysians
}

\author{
Y F Ngeow, S P Rachagan, S Ramachandran
}

\begin{abstract}
A single antigen indirect immunofluorescence test was used to screen for chlamydial antibody among Malaysian infants, children, sexually active adults and prostitutes. Of 794 serum samples tested, $361(45 \cdot 5 \%)$ were positive. Seropositivity increased with age and sexual activity and ranged from 10 to $16 \%$ among children under 10 years old to 94.4\% among prostitutes. Pregnant women and female adolescents showed a higher antibody prevalence than nonpregnant and older women. Six $(13 \%)$ infants under 6 months of age were positive for chlamydial IgM.
\end{abstract}

Chlamydial serology, though generally considered to be of little use as a diagnostic tool in individual patients, has been shown to play an important part in defining the epidemiology of chlamydial infection. Seroepidemiological surveys have helped to define the prevalence of asymptomatic chlamydial infections and the association of Chlamydia trachomatis with extra-genital syndromes. ${ }^{1}$

In tropical countries there is usually a lack of accurate data on the prevalence of chlamydial infections as facilities for the isolation of $C$ trachomatis are rather limited. Several epidemiological surveys have indicated that chlamydial genital tract infections may be as common as or more common than those occurring in developed countries. ${ }^{23}$ This paper describes the extent of exposure to chlamydial organisms among some sections of the Malaysian community.

\section{Methods}

The study population was predominantly urban Chinese $(86 \%)$ from the capital city of Kuala Lumpur and the adjacent town of Petaling Jaya and included the following: (a) 251 male and 234 female patients of all ages with no overt signs and symptoms of genital tract infection; (b) 101 women attending antenatal clinics; (c) 46 infants under 6 months old who were screened for congenital defects and intrauterine or perinatal infections; (d) 108 prostitutes including 11 homosexual men; and (e) 54 men attending a private sexually transmitted disease (STD) clinic, all of whom gave a history of extra-marital sex, mainly with prostitutes.

Blood was collected by venepuncture and all sera were kept at $-20^{\circ} \mathrm{C}$ before being tested Sera were tested for the presence of chlamydial antibody by the indirect fluorescent antibody staining technique using the Chlamydia-Spot IF Kit (BioMèrieux, France) which uses an inactivated, egg-grown $C$ trachomatis serotype $\mathrm{L} 2$ as the antigen and fluorescein isothiocyanate (FITC) labelled anti-human globulin conjugate. Test procedures were carried out according to the manufacturer's instructions. Infant sera were also tested for the presence of specific IgM antibody using a FITC-labelled anti-human IgM globulin conjugate. Serum dilutions used for screening were $1 / 16$ for male patients, 1/64 for female patients and neonates of both sexes, and 1/8 for the chlamydial IgM test. Positive sera were not titrated out further. Control positive and negative serum samples were included with each run.

\section{Results}

A total of 794 serum samples collected over a period of one year from August 1988 to July 1989 were tested, of which $361(45.5 \%)$ were regarded as positive. Age specific rates of antibody titre are shown in the table. For both sexes, with the exception of adolescents, there was a general increase in antibody prevalence with age, from 10-16\% among children under 10 years, to $>70 \%$ among adults over 50 years. Seropositivity in men seemed to reach a plateau after 30 years of age, but for women, there was an unexplained sharp increase in antibody prevalence after 50 years of age. The influence of sexual activity was obvious as prostitutes and their clients showed significantly higher antibody prevalence than the non-STD population studied ( $p<0.01)$. Pregnant women often had higher titres of antibody than their age matched controls. Young women (11-20 years) consistently showed higher seropositivity than older women whether they were students, antenatal mothers, or prostitutes.

Among 46 infants (newborn to 6 months old), $18(39 \%)$ were positive for IgG and six $\left(13^{\circ}\right)$ were positive for IgM. The IgG prevalence among infants was similar to that among antenatal women and probably reflected transplacental transfer of immunoglobulins. Of the six sera positive for IgM, however, five were from neonates less than 2 weeks old, suggesting intrauterine infection.

\section{Discussion}

The microimmunofluorescence test developed by Wang and Grayston for immunotyping $C$ trachomatis has been widely applied for seroepidemiological surveys. ${ }^{4}$ The original method uses all 15 immunotypes as antigen to show a 
Table Distribution of chlamydial antibodies by age group

\begin{tabular}{|c|c|c|c|c|c|c|c|}
\hline \multirow[b]{2}{*}{ No tested $\left({ }^{\circ}\right.$ o positive) } & \multicolumn{7}{|c|}{ Age (years) } \\
\hline & $0-10^{\star}$ & $11-20$ & $21-30$ & $31-40$ & $41-50$ & $>50$ & Total \\
\hline $\begin{array}{l}\text { Males } \\
\text { Females (non-pregnant) }\end{array}$ & $\begin{array}{l}37(16 \cdot 2) \\
30(10)\end{array}$ & $\begin{array}{l}66(28 \cdot 8) \\
43(25 \cdot 6)\end{array}$ & $\begin{array}{l}44(36 \cdot 4) \\
40(7 \cdot 5)\end{array}$ & $\begin{array}{l}37(62 \cdot 2) \\
48(14 \cdot 6)\end{array}$ & $\begin{array}{l}31(61 \cdot 3) \\
34(24 \cdot 2)\end{array}$ & $\begin{array}{l}36(72 \cdot 2) \\
39(66 \cdot 7)\end{array}$ & $\begin{array}{l}251(43 \cdot 4) \\
234(24 \cdot 8)\end{array}$ \\
\hline $\begin{array}{l}\text { Females attending antenatal } \\
\text { clinic } \\
\text { Prostitutes } \\
\text { Males attending STD clinic }\end{array}$ & & $\begin{array}{l}12(50) \\
22(95 \cdot 5)\end{array}$ & $\begin{array}{l}56(32 \cdot 1) \\
63(92 \cdot 1)\end{array}$ & $\begin{array}{l}33(33 \cdot 3) \\
17(100)\end{array}$ & $6(100)$ & & $\begin{array}{l}101(34 \cdot 7) \\
108(94 \cdot 4)\end{array}$ \\
\hline No tested ( ${ }^{\circ}$ positive) & & $21(71 \cdot 4)$ & $20(60 \cdot 0)$ & $8(87 \cdot 5)$ & $3(100)$ & $2(100)$ & $54(72 \cdot 2)$ \\
\hline
\end{tabular}

Excludes infants under 6 months of age

A positive titre for men is $\geqslant 1 / 16$; a positive titre for women is $\geqslant 1 / 64$.

serotype specific antibody response to $C$ trachomatis infection. Subsequently, microimmunofluorescence crossreactions were found between $C$ trachomatis and $C$ psittaci ${ }^{5}$ and between $C$ trachomatis and $C I O L-207^{6}$ which had been shown to be antigenically related to the new chlamydia organism, $C$ $T W A R .^{7}$ With wider use of the microimmunofluorescence test, it soon became clear that antibodies of broad specificity often exist in patients' sera and that the microimmunofluorescence test can probably detect both group specific as well as type specific antibodies. $^{8}$ This made it possible and more convenient to use a single broadly reacting antigen to screen for chlamydial antibody. Indeed, it has been shown that single antigen immunofluorescence tests can be as sensitive as the microimmunofluorescence test, although they are slightly inferior in specificity. ${ }^{9}$

In this study the antigen used in our indirect immunofluorescence test was LGV 2 which belongs to the BEDL group of related strains responsible for most genital chlamydial infections in Europe. The antibodies we detected probably reflected the prevalence of both sexually transmitted and non-sexually transmitted chlamydial infections in our population.

Our findings showed many similarities with seroepidemiological data from Western industrialised countries. As reported in the United States, ${ }^{10}$ we found antibody prevalence to be correlated with age and sexual activity. Like Mardh ${ }^{11}$ and Brunham, ${ }^{12}$ our results suggested that female adolescents were more susceptible to chlamydial infection than older women whether they were pregnant or not. There were also indications that pregnancy itself might be a risk factor for chlamydial infection, possibly as a result of hormonal changes and the immunosuppression that occurs during pregnancy.

Using a screening dilution of $1 / 8$, Schachter found a $20-25 \%$ antibody prevalence among asymptomatic, sexually active adult men in San Francisco. ${ }^{13}$ Using a higher screening dilution of $1 / 16$, we obtained an even higher antibody prevalence of 36.4 to $62.2 \%$ among men aged 21 to 40 years. Antibodies to $C$ trachomatis have been reported to occur more often and in higher titres in women than in men. ${ }^{14}$ From studies correlating antibody titres with isolation rates, it has been suggested that a titre of $1 / 64$ in women with cervicitis may indicate current chlamydial infection. ${ }^{15}$ Hence we screened our women at a $1 / 64$ serum dilution for possible clinical infection but found that even at this higher titre, seropositivity was common among totally asymptomatic women.

Among people who are not sexually active chlamydial infection is fairly common: seropositivity rates of $>20 \%$ have been reported for celibate nuns, women with no history of sexual intercourse, and prepubertal children with no evidence of sexual abuse. ${ }^{16}$ Grayston found a seroconversion rate of 2-3\% among young children in Seattle, United States of America. ${ }^{1}$ Chlamydial antibodies in these populations could be the result of extragenital infections of $C$ trachomatis which has been potentially associated with pharyngitis, otitis media, pneumonia, ${ }^{17}$ endocarditis, ${ }^{18}$ and meningoencephalitis. ${ }^{19}$ The mode of transmission in these infections is not yet clear. A small proportion of antibodies detected by immunofluorescence could also be caused by $C$ psittaci or $C T W A R$ infections. The former is an established respiratory tract pathogen; the latter has been increasingly recognised as a cause of acute respiratory infections. ${ }^{20}$ Malaysia is not known to be endemic for trachoma, but acute respiratory infections are very common. In this study $50 \%$ of children under 10 years, $30^{\circ}$ of adolescent boys, and $40^{\circ}{ }_{0}$ of adolescent girls had a clinical diagnosis of viral fever. Of the seropositive children and adolescents, $40^{\circ}{ }_{0}$ and $20^{\circ}$, respectively, were IgM positive for chlamydia. It is reasonable to postulate that a considerable proportion of our acute respiratory infections have a chlamydial aetiology. Another possible explanation for the seropositivity among children with febrile illness is that the febrile illness could have reactivated a latent chlamydial infection acquired perinatally.

Perinatal infection is common among infants born to infected mothers, but the role of $C$ trachomatis in intrauterine infection is less well established. Although five of our neonates under 2 weeks old were chlamydial IgM positive, suggesting intrauterine infection, it must be borne in mind that an indirect immunofluorescence test can detect fetal IgM produced against maternal IgG and not against $C$ trachomatis. $^{21}$

In conclusion, our data indicate that chlamydial infection is widespread among Malaysians and support our clinical impression that chlamydial genital infection is common among sexually active adults. The high antibody prevalence among pregnant women suggests a need to consider antenatal screening for chlamydial genital infection and follow up of 
exposed infants for consequences of perinatal infection. Our management of acute respiratory infections should perhaps also include investigation for a chlamydial aetiology.

This study was supported by China Medical Board Grant No 30205 (AQ).

1 Grayston JT, Wang SP, Foy HM, Kuo CC Seroepidemiology of Chlamydia trachomatis infections. In: Mardh PA, Holmes KK, Oriel JD, Piot P, Schachter J, eds. Chlamydial infections. Amsterdam: Elsevier eds. Chlamydial infections.

2 Darougar S, Forsey T, Osoba AO, Dines RJ, Adelusi B. Coker GO. Chlamydial genital infection in Ibadan, Nigeria. A seroepidemiological survey. Br J Vener Dis 1982;58:366-9.

3 Forsey T, Darougar S, Dines RJ, Wright DJM, Friedmann PS. Chlamydial genital infection in Addis Ababa, Ethiopia. A seroepidemiological survey. $\mathrm{Br} J$ Vener Dis 1982;58:370-3.

4 Wang SP, Grayston JT. Immunologic relationship between genital TRIC, Lymphogranuloma venereum and related genital TRIC, Lymphogranuloma venereum and related
organisms in a new microtitre indirect immunofluoresorganisms in a new microtitre indirect immuno

5 Myhre EB, Mardh PA. Antibody response in psittacosis. In: Mardh PA, Holmes KK, Oriel JD, Piot P, Schachter J, eds. Chlamydial infections. Amsterdam: Elsevier Biomedical Press, 1982:345-8.

6 Darougar S, Forsey T, Brewerton DA, Rogers KL Prevalence of antichlamydial antibody in London blood donors. Br J Vener Dis 1980;56:404-7.

7 Dwyer RStC, Treharne JD, Jones BR, Herring J. Chlamydial Infection. Results of microimmunofluorescence tests for detection of type-specific antibody in cence tests for detection of type-specific antibody in
certain chlamydial infections. Br J Vener Dis 1972;48: certain

8 Thomas BJ, Reeve P, Oriel JD. Simplified serological test for antibodies to Chlamydia trachomatis. J Clin Microbiol

9 Richmond SJ, Caul EO. Single antigen indirect immunofluorescence test for screening venereal disease clinic populations for chlamydial antibodies. In: Hobson D,
Holmes KK, eds. Nongonococcal urethritis and related Holmes KK, eds. Nongonococcal urethritis and related
infections. Washington, DC: American Society for infections. Washington, D
Microbiology, 1977:259-65.

10 Stamm WE, Holmes KK. Chlamydia trachomatis infections of the adult. In: Holmes KK, Mardh PA, Sparling PF, Wiesner PJ, eds. Sexually transmitted diseases. New York: McGraw Hill Book Company, 1984:258-70.

11 Mardh PA, Helin I, Bobeck S, Laurin J, Nilsson T. Colonization of pregnant and puerperal women and neonates with Chlamydia trachomatis. Br J Vener Dis 1980;56:96-100.

12 Brunham RC, Holmes KK, Eschenbach D. Sexually transmitted diseases in pregnancy. In: Holmes KK, Mardh PA, Sparling PF, Wiesner PJ, eds. Sexually transmitted diseases. New York: McGraw Hill Book Company, eases. New $1984: 782-816$.

13 Schachter J. Biology of Chlamydia trachomatis. In: Holmes KK, Mardh PA, Sparling PF, Wiesner PJ, eds. Sexually transmitted diseases. New York: McGraw Hill Book Company, 1984:243-57.

14 Mardh PA. Bacteria, chlamydia and mycoplasmas. In: Holmes KK, Mardh PA, Sparling PF, Wiesner PJ, eds. Sexually transmitted diseases. New York: McGraw Hill Book Company, 1984:829-56.

15 Darougar $S$, Treharne JD. Chlamydial infections: laboratory aspects. In: Harris JRW, ed. Recent advances in laboratory aspects. In: Harris JRW, ed. Recent advances in
sexually tramsmitted diseases. Vol 2 . London: Churchill sexually tramsmitted diseases.

16 Black SB, Grossman M, Cles L, Schachter J. Serologic evidence of chlamydial infection in children. $J$ Pediatr 1981;98:65-7.

17 Paran H, Heimer D, Sarov I. Serological, clinical and radiological findings in adults with bronchopulmonary infections caused by Chlamydia trachomatis. Israel J Med Sci $1986 ; 22: 823-7$.

18 van der Bel-Kahn JM, Watanakunakorn C, Menefee MG, Long HD, Dicter R. Chlamydia trachomatis endocarditis. Am Heart $J$ 1978;95:627-36.

19 Myhre EB, Mardh PA. Chlamydia trachomatis infection in a patient with meningoencephalitis. $N$ Engl Med J patient with

20 Saikku P, Ruutu P, Leinonen M, Panelius J, Tupasi TE, Grayston JT. Acute lower respiratory tract infection associated with chlamydial TWAR antibody in Filipino children. J Infect Dis 1988;158:1095-7.

21 Reimer CB, Black CM, Phillips DJ, et al. The specificity of fetal IgM: antibody or anti-antibody? Ann N Y Acad Sci 1075;254:77. 